\title{
Situaciones que facilitan o dificultan la escritura de tesis de posgrado
}

\author{
Lady Villabona Osorio ${ }^{1}$ \\ ladyvillabona@gmail.com
}

Rec. 18/12 2017 Apr. 25/04 2018

\begin{abstract}
Resumen
Estudios sobre maestrandos que aprueban todos los cursos, pero no obtienen su título o tardan demasiado en ello, muestran que el cuello de botella se concentra en la elaboración de la tesis, o que al llegar la tesis se produce la deserción en el posgrado, debido al insuficiente acompañamiento durante el proceso de formulación y escritura de la tesis. Los datos reafirman la necesidad de realizar cambios organizacionales en las maestrías, y se describen escenarios facilitadores para la escritura de las tesis en Argentina y Colombia.
\end{abstract}

Palabras claves: tesis - investigación - posgrados - universidad.

\begin{abstract}
Studies on masters estudent who pass all the courses, but do not obtain their degree or take too long in it, show that the bottleneck is concentrated in the elaboration of the thesis, or that when the thesis comes the desertion occurs in the postgraduate, due to the insufficient accompaniment during the formulation and writing process of the thesis. The data reaffirm the need to make organizational changes in the master's degrees, and facilitating scenarios for the writing of the theses are described in Argentina and Colombia.
\end{abstract}

Palabras clave: tesis - reserch - posgraduate - university.

\section{Introducción}

La oferta de programas de posgrado en países como Colombia y Argentina ha venido en aumento, pues la formación posgradual ha cobrado relevancia entre los profesionales. Muchos colombianos por motivos económicos realizan su maestría en alguna de las universidades nacionales argentinas. Mientras que en una universidad pública en Colombia un máster puede costar alrededor de $\$ 20$ millones (US\$10.700), en Buenos Aires la tarifa puede bajar más del 50\%”, explicó el periódico. El medio también resaltó las "facilidades en la reglamentación migratoria" de Argentina. 
No obstante, datos como los del Banco Mundial (2012) muestran una baja tasa de graduación en los posgrados en Colombia, ya que para el año 2010, 23.808 personas estaban matriculadas en una maestría, pero apenas 5.861 obtuvieron su título y sólo 208 de los 2.326 estudiantes de doctorado se titularon, en Argentina, alrededor del 50\% de los alumnos de posgrado dejan la carrera sin terminar o en el mejor de los casos postergan la graduación, Krizanovic (2015).

Ligia Ochoa (2009), de la Universidad Nacional de Colombia, afirma que la tesis principalmente, pone en riesgo la titulación de los estudiantes de maestría:

A pesar del número creciente de maestrías en la última década en Colombia y América Latina, las tasas de graduación no parecen corresponder ni al nivel de ingreso ni a la expectativa de egreso de un programa normal de maestría. Si bien hay múltiples factores que explican la baja tasa de terminación, investigaciones como la de Carlino (2008b) muestran que un aspecto determinante está relacionado con las tesis. (Ochoa \& Cueva, 2012, p. 11)

Este fenómeno resulta también habitual en países de habla inglesa donde se le ha denominado $\mathrm{ABD}$ (all but dissertation) refiriéndose a aquellos alumnos que han terminado "todo excepto de la tesis". En Colombia el informe del Sistema para la Prevención de la Deserción en Educación Superior (SPADIES), sobre los estudiantes que ingresaron a especializaciones, maestrías y doctorados desde el año 2009 hasta el 2011, revela que "En el caso de las maestrías, se reconoce un salto importante en el paso de tercer a cuarto semestre, donde la deserción aumenta en 19 puntos, lo que puede estar asociado al tema de trabajo de grado" (Durán, 2015, p. 1). Se señala además que en las áreas de conocimiento en las cuales se presenta baja tasa de deserción son matemáticas y ciencias naturales.

El Ministerio de Educación Nacional de Colombia, (MEN) sigue avanzando identificación de las variables de mayor incidencia en la deserción de los estudiantes de posgrado para orientar las acciones de política pública frente al tema.

En el sector estatal de Argentina las ciencias sociales representan una tasa de graduación inferior con respecto al número de graduados en ciencias de la salud, (Recalde, 2015), en relación a esto Carlino, (2005), muestra que los estudiantes en las ciencias humanas perciben escaso apoyo y acompañamiento por parte de las instituciones y/o de sus directores.

Miembros del Departamento de Humanidades y Artes de la Universidad Nacional de Lanús, mencionaron que el insuficiente acompañamiento durante el proceso de formulación y escritura de tesis y trabajos finales, es una de las dificultades más habituales. Según el grupo de investigación de lingüística de la UBA, los escenarios dispuestos por las instituciones para apoyar procesos de escritura de tesis llamados seminarios de tesis o de escritura de tesis "no llegan a cubrir toda la necesidad de soporte e intercambio que precisa la labor del tesista" (Di Estefano 2003, citado por Carlino).

Para estudiar este fenómeno se ha adoptado una perspectiva socio cultural, ya que al igual que Carlino \& Reisin (2009), se considera que el éxito o el fracaso con la elaboración 
de la tesis, no es atribuible a condiciones individuales del tesista, lo cual se sostiene en el concepto de aprendizaje no como mero cambio individual [bien sea en conducta o en sistemas de conocimiento), sino como "cambios en las formas de comprensión y participación de los sujetos en una actividad conjunta" (Baquero, 2006, p. 46), "cambios en la participación de las personas en la práctica social, en el contexto de comunidades de práctica" (Larrreamendy, 2011, p. 37). Las comunidades de práctica definidas como conjuntos de participantes que comparten una comprensión de lo que están haciendo y de lo que ello significa para sus vidas y para la vida misma de la comunidad. (Larreamendy, 2011, p. 37)

El aprendizaje, se trate del aprendizaje escolar del aprendizaje en el contexto de situaciones tutoriales (apprenticeship), es en cualquier caso un fenómeno situado, en el sentido de hacer parte de las dinámicas propias, transformativas o reproductivas, de una práctica social. (Larreamendy, 2011, p. 36-37)

Tal postura, no establece escisiones entre el sujeto y su entorno, y coloca en el centro de los análisis y de las intervenciones educativas, las situaciones y no al individuo, pues las posibilidades de desarrollo y aprendizaje no son un atributo personal, sino que son las situaciones educativas las que son capaces o no de producirlo.

Lave y Wenger (1991) ofrecen, una visión del aprendizaje como proceso estrechamente relacionado con la práctica social, ellos estudiaron los procesos de aprendizaje de niñas tejedoras en una comunidad indígena de Guatemala, donde no cuentan con escuelas formales o "procesos de enseñanza aislados" que les permitan a las niñas adquirir las habilidades que requieren para trabajar con sus madres como tejedoras, los hallazgos revelaron que hay un tipo de aprendizaje " [...] Que ocurre en el seno de una actividad auténtica, especialmente anclado en la interacción social, en la actividad conjunta [joint practice] procede fundamentalmente a través de andamiaje [scaffolding], en vez de instrucción explícita" (Larreamendy, 2007, p. 6)", que en inglés recibe el nombre de "apprenticeship”.

Apprenticeship en inglés, término que se utiliza para referirse al aprendizaje práctico, como el que se da en las actividades artesanales, manuales, etc. En castellano utilizamos la palabra aprendizaje tanto para designar el proceso cognitivo-individual (learning) como el práctico- social. (Rogoff, 1997, p. 1)

La participación en las actividades de una comunidad de práctica es progresiva por lo que existen dos tipos de participantes, periférico y central, al primero le son asignadas tareas auténticas pero en ellas hay mayor tolerancia al error, y al segundo tipo se le encargan tareas que tienen un efecto más notorio en la comunidad.

Participación periférica legitima" permite hablar de relaciones entre novatos y veteranos y de las actividades, identidades, artefactos, y comunidades de conocimiento y práctica. Trata de un proceso por el que los nuevos participantes se convierten en parte de una comunidad de práctica. (Lave $\&$ Wenger, 1991, p. 29) 
En sintonía con esta línea, Carlino (2005) propone "enseñar practicas situadas" en oposición al enfoque de "enseñar habilidades fragmentarias o descontextualizadas" el cual, se centra en aquello que los estudiantes saben o no hacer con la lectura y la escritura, independiente del contexto en el cual lo hicieran, mientras que entender la lectura y la escritura como prácticas sociales y situadas permite centrar la atención en aquello que todos los docentes pueden hacer para enseñarles a sus alumnos a leer y escribir a través del currículo. De este modo, la escritura de la tesis se facilita al ser propuesta como una actividad en la que participan los miembros de una "comunidad de práctica" de manera conjunta (joint practice), en la que los aprendices "tesistas" van ganando "centralidad" en sus comunidades de práctica a partir de la realización de "tareas científicas genuinas" con científicos más experimentados, para de este modo introducirse en una nueva cultura: la "cultura científica e investigativa”, pues en términos de Carlino elaborar una tesis consiste en:

[...] un proceso paulatino de adentramiento a una cultura nueva (Zeegers y Barron, 2000), la cultura investigativa de una determinada comunidad disciplinar, con métodos y formas de análi- sis argumentación y discurso específicos (Knight, en prensa; Street, 1999), Y como todo un aprendizaje de tamańa envergadura, requiere no sólo un compromiso personal del aprendiz sino un soporte externo que andamiaje el proceso (Love y Street, 1998). Un soporte institucional tan- to como un soporte corporeizado en la experiencia y dedicación del director de tesis. (Carlino, 2005, p. 418)

La ciencia como cultura, se refiere a un "conjunto de prácticas epistémicas y discursivas compartidas por una comunidad” (Latour \& Woolgard, 1986; Pera, 1994; Pickering, 1993; Schwab, 1962, citado por Larreamendy 2007), esto quiere decir, formas de interrogar, representar, explicar la realidad, de argumentar y socializar el conocimiento, que son propias de cada disciplina científica, lo opuesto a definir la ciencia sólo "por una serie de prescripciones heurísticas (como plantea el positivismo científico) (Larreamendy, 2007, p. 5)

La tesis siendo una actividad compartida y no solitaria exige la transformación de las maestrías en "microcomunidades de aprendizaje" Reisin \& Carlino (2009), puesto que cuando se presenta la tesis por fuera de la organización institucional, las actividades investigativas propuestas al tesista no obedecen a "auténticas prácticas", para esto, es necesario la inserción de los tesistas en líneas y grupos de investigación, en grupos de pares para el seguimiento sistemático de las tesis, o círculos de escritura de tesis, entre otros, pues la finalización exitosa de la tesis es:

[...] el resultado de la interacción entre los actores institucionales, en situaciones contextuales "autenticas" que los involucran, cuando se relacionan entre sí, en torno a prácticas particulares. (Lave 2001, citado por Carlino \& Reisin, 2009)

\section{Métodos y Materiales}

Se ha optado por la perspectiva metodológica de Juan Samaja (2010) que propone 3 niveles implicados en la construcción del dato científico, en el nivel supra unitario y 
en el de anclaje, se usa la técnica documental de recolección de información basada en documentos oficiales, que contienen los planes y programas de 2 maestrías acreditadas, una de Colombia y otra de Argentina, y las normativas de posgrado de ambos países. En el nivel subunitario se utiliza una encuesta para obtener información sobre lo que consideran los alumnos acerca de la escritura de la tesis y se entrevistan directivos y docentes.

La estructura del dato representada en la matriz es "de carácter universal reconocible en todo tipo de datos" (Ynoub, 2015, p. 228), los elementos que la componen están presentes tanto en datos de naturaleza cualitativa como cuantitativa, el indicador permite la "[...] intermediación por la cual se tornan observables ciertos conceptos teóricos.” (Samaja 2010, p. 181).

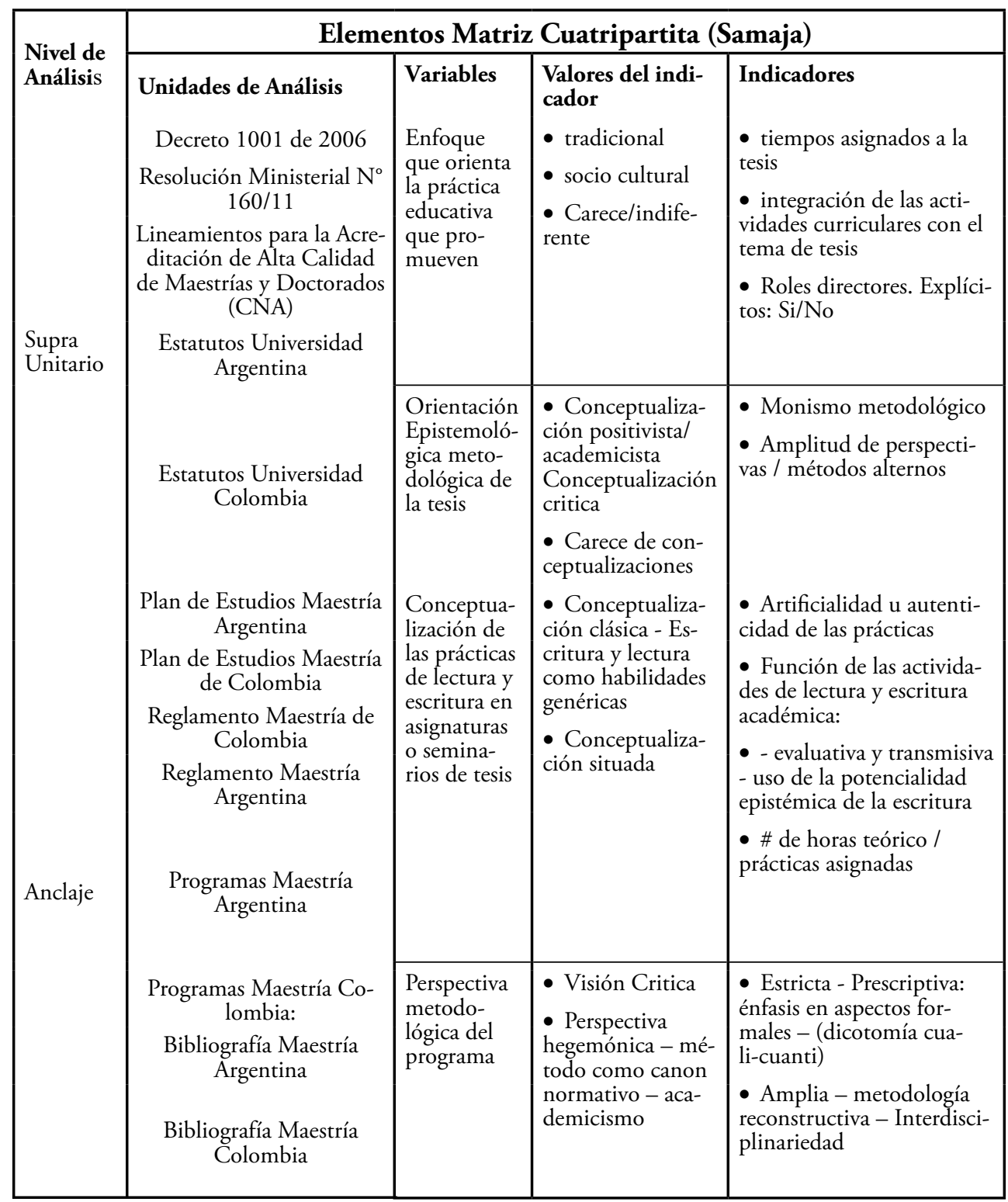




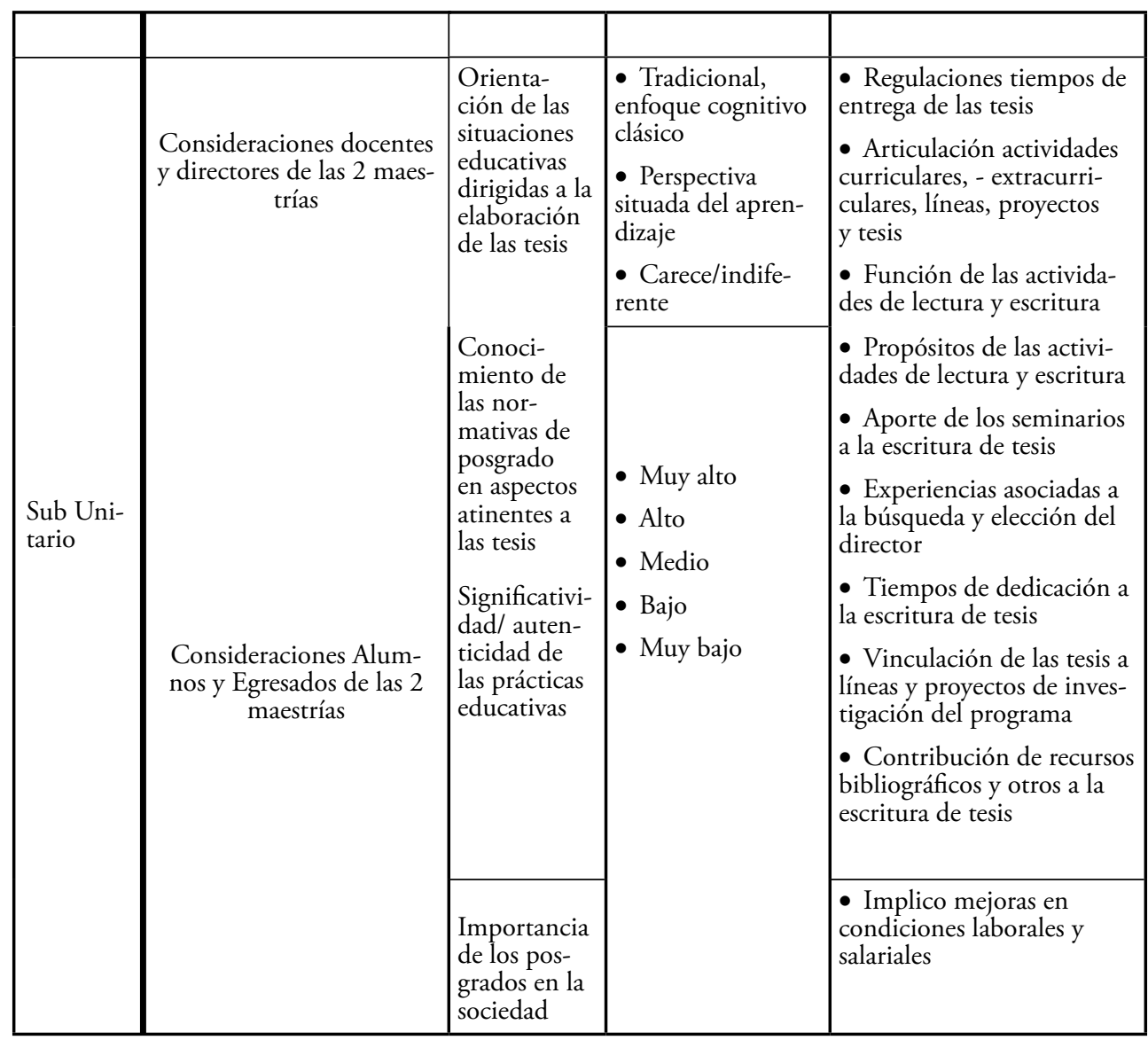

Figura 1. Matriz de Datos Samaja

\section{Resultados Análisis Nivel Supraunitario}

En este nivel la variable se refiere al enfoque que orienta las prácticas educativas implícitas en los documentos, los valores según la teoría socio cultural son: tradicional o situado, y se determinan en función de los indicadores: tiempos asignados a la tesis e integración de las actividades curriculares con el tema de tesis.

Tanto las estructuras curriculares como la carga horaria se tratan en el punto 3 de la resolución 160 del 29 de diciembre del 2011 de Argentina, allí se especifica que a diferencia de las maestrías profesionales y las especialidades, las maestrías académicas y doctorados pueden tener una estructura curricular personalizada, esto quiere decir que "se define para cada estudiante sobre la base del área de conocimiento y tema del trabajo final", no obstante esto no es de carácter obligatorio, pues el programa analizado pese a ser académico cuenta con una semiestructurada, y por ende, son menores los tiempos destinados a actividades curriculares directamente relacionadas con las tesis o los trabajos finales. 
Con respecto a las cargas horarias la resolución establece que:

[...] las carreras de Maestría tendrán al menos 700 horas reloj de las cuales, un mínimo de 540, deberán destinarse a cursos, seminarios y otras actividades de esa índole y las restantes, podrán ser asignadas al trabajo final $\mathrm{u}$ otras actividades complementarias.

Estas restantes equivalen apenas a unas 160 horas que podrían estar destinadas al trabajo final (tesis) u otras actividades que la universidad considere, lo cual evidencia que la normativa no exige a las instituciones que ofertan estos posgrados tiempos significativos de dedicación a las tesis. Los lineamientos de acreditación de alta calidad para los posgrados en Colombia, aunque no estipulen tiempos específicos para el desarrollo de los trabajos de grado, ni aspectos relacionados con las direcciones de tesis, en su numeral 7 y 8 le exige a las instituciones que garanticen "condiciones para el acceso permanente por parte de estudiantes y docentes a prácticas necesarias para adelantar procesos de investigación en el programa”, por su parte, la normativa Argentina, establece que el programa debe plasmar en un reglamento interno, todo lo referido a las direcciones de tesis.

$\mathrm{Al}$ analizar el capítulo VI artículo 13 de la normativa Colombiana, se identifican algunas contrariedades, pues el decreto denomina a uno de los dos tipos de maestrías "maestría de investigación", a pesar de que todos los posgrados para acreditarse, independiente de su clasificación, deben cumplir, con unas condiciones mínimas de calidad entre ellas la investigación, además la "maestría de profundización" no es ajena al proceso de producción de conocimiento científico, de hecho el artículo 6 del decreto 1001, plantea que "El trabajo de grado de estas maestrías podrá estar dirigido a la investigación aplicada, el estudio de casos, la solución de un problema concreto o el análisis de una situación particular". Lo anterior abre el interrogante acerca del modo de conceptualizar el tipo de investigación realizada en las maestrías de profundización, y hasta qué punto este difiere con la "investigación académica”, ya que según el artículo 6 del decreto, son las maestrías de investigación aquellas encargadas de desarrollar las competencias propias de un "investigador académico".

Con respecto a los estatutos, particularmente los de la Universidad Argentina de manera explícita en su artículo 14 se refieren a la enseñanza y el aprendizaje, exigiendo la integración entre la teoría y la práctica en dichos procesos, lo cual constituye un principio del enfoque situado, aprehender y hacer como acciones inseparables Díaz (2003), mientras que en los estatutos de la institución Colombiana no se explicitan aspectos relacionados con cierto enfoque que oriente las prácticas educativas, por lo tanto se supone indiferencia de la institución por estos asuntos.

\section{Análisis del Nivel de Anclaje Reglamentos de tesis y de posgrado}

En el análisis de los documentos del nivel de anclaje, la variable enfoque que orienta la práctica educativa vuelve a cobrar importancia, y a partir los indicadores: a) direcciones de tesis y b) tiempos asignados a las tesis, se asignan los valores respectivos. 
Es de anotar que, en Argentina por resolución, cada programa cuenta con un reglamento interno, en el de la "MIC" sigla usada para denominar la maestría argentina, la elección del director de tesis, se entiende como una responsabilidad que recae principalmente en el estudiante.

Capítulo 1: Director de tesis. Artículo 1 - Elección.

"El Director de Tesis será seleccionado por el maestrando y deberá tener título de posgrado equivalente o mayor al otorgado por la carrera, o méritos equivalentes"

Esta tarea que el maestrando debe realizar sin el suficiente apoyo institucional, evidencia el estado de soledad que experimentan los tesistas y que es percibido como obstaculizador para quienes no integran un grupo de investigación o no cuenten con experiencia previa en ella (Carlino, 2005).

En la universidad colombiana, el acuerdo No. 15 (06 de julio de 2006) por el cual se reestructura el reglamento de los Estudios de Postgrado y de los respectivos trabajos de grado, determina en el artículo 52 que el director será un docente "recomendado por el comité curricular ante el consejo de facultad y en el artículo 53 continúa diciendo que "Cuando el estudiante acumule el $20 \%$ de ausencias no justificadas a los compromisos pactados, cesará la responsabilidad del asesor del trabajo de grado".

ARTICULO 52. Todo trabajo de grado tendrá un asesor, docente en ejercicio, mínimo con título de postgrado en un área relacionada con la especialidad, recomendado por el Comité Curricular ante el Consejo de Facultad.

Acerca del tiempo asignado a las tesis, el artículo 7 del reglamento de la MIC establece la entrega de un plan de tesis para su presentación oficial ante el programa, posterior a la finalización y aprobación de todos los módulos incluido el seminario de tesis, esto quiere decir que, el estudiante somete a aprobación su plan de tesis hasta culminar todos los módulos, por lo tanto, durante toda la cursada sólo podrá avanzar en la elaboración de un plan de tesis, pero poco en la ejecución de este.

ARTICULO 7. Presentación del plan de Tesis

A partir de la finalización y aprobación de los seis (6) Módulos, incluyendo el Seminario de Tesis, el maestrando deberá presentar el plan de tesis (o anteproyecto) debidamente justificado y el nombre del Director. [...]

Dicho hallazgo coincide con el de Reisin \& Carlino, (2009) basadas en Rogoff, 1997; Love, 1998, “[...] la tesis se presenta por fuera de la organización institucional quedando desintegrada del contexto cultural en donde las actividades investigativas se convierten en prácticas educativas "auténticas" (p. 370), Rogoff (1997) plantea que el aprendizaje se "[...] centra en un sistema de implicaciones y acuerdos en el que las personas se integran en una actividad culturalmente organizada en la que los aprendices se convierten en participantes más responsables". (p. 4) 
El reglamento de la universidad de Colombia, en el artículo 5 establece que el desarrollo del plan de estudios cubre además de las asignaturas, el trabajo de grado, tal cobertura implicaría entonces, que el trabajo de grado pueda realizarse durante el tiempo de duración del plan de estudios del programa, es decir máximo 2,5 años.

ARTICULO 5. El desarrollo de los planes de estudio se realizará por periodos académicos definidos y cubre asignaturas, actividades dirigidas y trabajo de grado

[...] La duración de los planes de estudio debe mantenerse en los siguientes rangos: Especialización 1 a 1.5años

Maestría 1.5 a 2.5años

Sin embargo, este reglamento no explicita el número de créditos, ni los tiempos de dedicación al proyecto de grado, ni tampoco como este se integrará a las actividades curriculares. "PARAGRAFO: El número de créditos académicos asignados al proyecto de grado será especificado en el Acuerdo de creación del programa”.

Según el artículo 51 el que determina los requisitos para la presentación del anteproyecto del trabajo de grado es el consejo de facultad, en este artículo a su vez se establece a quien deberá ser entregado, pero no especifica en qué momento dentro del desarrollo del plan de estudios.

ARTICULO 51. El anteproyecto del trabajo de grado se presentará para su evaluación, en copia escrita y electrónica al Comité Curricular, quien lo evaluará y recomendará al Consejo de Facultad cumpliendo con los requisitos que para su presentación determine este.

Además, de acuerdo con lo estipulado en su artículo 32, el plan de estudios no alcanzaría a cubrir todo el tiempo requerido para el desarrollo de la tesis, ya que menciona que "El tiempo de realización de los estudios, incluyendo la tesis o el trabajo de grado, será máximo el doble de la duración normal del programa, contados a partir de la fecha de su iniciación" esto equivale a 5 años, y si pasado este tiempo el estudiante no ha culminado su tesis deberá pagar el valor equivalente a una asignatura. Por su parte, el reglamento de la MIC habla de 2 años máximo para entrega de la tesis, después de aprobar el plan de tesis y no se refiere a pagos extras.

Este último reglamento, en su numeral 3.3 señala que la función del director de tesis es apoyar al estudiante en la elección del tema de tesis, "el cual es de libre elección", no obstante Carlino (2005) ha mostrado que un contexto facilitador para la escritura de tesis implica que los temas vengan dados por el programa de investigaciones en el que el estudiante debería insertarse desde el inicio de la maestría, ya que "de este modo, el problema que estudia puede ser identificado casi de entrada y está vinculado a los temas de otros compañeros de equipo" (p. 5) de otro modo, el estudiante que tenga dificultades en la solitaria búsqueda de director, carecería del apoyo requerido para la identificación de posibles temas y para el recorte y delimitación de los mismos. 


\section{Programas}

Se analizaron aquellos que por su denominación se enfocan directamente en el proyecto de grado o tesis, y tienen un alto componente investigativo que contribuye a su elaboración, nuevamente se tiene como variable el enfoque que orientará las prácticas educativas, y sus valores situado o tradicional, un primer indicador se refiere a la autenticidad $\mathrm{u}$ artificialidad de las actividades que se proponen, $\mathrm{y}$ un segundo y último indicador es la función que cumplen las prácticas de lectura y escritura en estos programas.

El programa del "seminario de investigación" de la MCE plantea una metodología que busca llevar al maestrando a producir textos en relación al tema de su proyecto, lo cual es una función epistémica de la escritura en la medida que permite elaborar conocimientos y no sólo reproducir información (función evaluativa), pues el objetivo de este seminario "será precisar aún más la temática alrededor de la cual se construye la pregunta de investigación", y para ello el estudiante debe:

[...]Abordar bases de datos, para acercarnos a investigaciones que se han hecho sobre las intuiciones que tenemos, al finalizar el seminario, se tendrán identificados y copiados, al menos diez artículos, para ser leídos, y producir un texto, que tendrá los siguientes parámetros:

Cuál es la investigación propuesta por el autor.

Qué referencias teóricas alude.

Qué técnicas de recolección y análisis utilizó.

Y qué relación tiene con el tema de investigación propuesto.

Esperamos cumplir con esta programación para avanzar rápidamente en el problema y desarrollar así, todo el proyecto.

Téngase en cuenta que en este último apartado cuando se habla de proyecto se refiere a la tesis o al trabajo de grado del maestrando. Por el contrario, en el programa de la asignatura "mediciones y análisis de datos" de esta misma universidad, no hay una solicitud explícita de las tesis o trabajo de grado y en la metodología se proponen ejercicios sobre mediciones con problemas que pueden ser reales o hipotéticos, es decir que no necesariamente corresponden con aquellos que los estudiantes resuelven en sus tesis o trabajos de grado, dando cuenta así de la artificialidad la práctica educativa, característica de la metodología de enseñanza tradicional.

Igualmente en la MIC el modulo procesamiento y análisis de datos, pese a tener mayor intensidad horaria y una denominación que expresa el carácter práctico del mismo, de sus siete unidades sólo una implica una "revisión práctica de herramientas para el procesamiento de datos y el análisis de información" actividad que por tratarse de una mera revisión, y al no vincularse con la tesis, ni con investigaciones en curso en las que participe el maestrando, no garantizará un dominio de aquellas herramientas. Este tipo de prácticas educativas orientadas desde un enfoque tradicional se caracterizan por "la enseñanza de habilidades fragmentarias o descontextualizadas", tales como procesar y analizar datos por fuera de un contexto de auténtica práctica científica.

El modulo "seminario de tesis" de la MIC, pese a ser el único módulo que solicita al estudiante la presentación del último borrador del plan de tesis, propone la elaboración 
de este a modo de un simulacro que "permita simplemente apropiarse de los conocimientos para la elaboración de cualquier plan" lo cual es un indicador de un enfoque tradicional en la enseñanza de la investigación.

El plan puede corresponder con los temas que finalmente se presentarán para su aprobación, o ser un simulacro con temas que luego se cambiarán y que permita simplemente apropiarse de los conocimientos para la elaboración de cualquier plan. Se recomienda que los alumnos que están finalizando la cursada de la maestría adopten la primera modalidad. Se tomará un examen escrito con preguntas similares a las que se trabajaron durante la cursada. (Ambrosini \& Mombrú, 2013, p. 8)

Lo anterior también habla del uso que se le da a la escritura en este seminario de tesis pues una de las actividades de escritura más importante del curso y que sucede al final de este, se enfoca en la valoración de los contenidos propios del mismo mediante preguntas basadas en los textos solicitados, lo cual indica que aquí los procesos de escritura cumplen una función evaluativa. En este sentido, el objetivo de este seminario es procurar que el alumno "actualice y consolide las capacidades y las herramientas fundamentales para la redacción de su tesis" lo cual se basa en el supuesto de que el estudiante cuenta con una "habilidad básica de escritura generalizable" previamente adquirida, no obstante Arnoux (2005) señala que a diferencia de lo que sucede en las ciencias exactas, en el contexto de las ciencias sociales y humanas " [...] pocos tesistas han publicado con anterioridad y cuando lo han hecho, han escrito géneros más distantes del género tesis [...]" (p. 4), por ende, el ingreso a una nueva cultura impone nuevos retos discursivos al tesista, quien al participar en una determinada comunidad discursiva aprenderá las formas como esta hace uso del lenguaje.

[...] las nuevas comunidades de pensamiento y discurso que abren los posgrados exige, pues, adquirir no sólo novedosos sistemas de métodos y conceptos sino aprender a participar en sus prácticas características de producción de textos, asociadas a nuevas modalidades de analizar, organizar, "manipular" y pensar sobre el conocimiento. (Olson, 1998, en Arnoux, 2005, p. 3)

Arnoux \& Carlino, (2003) afirman que cuando los sistemas de posgrado presuponen en los alumnos una pericia escritora que los habilita para trabajar en forma independiente, estos consideran que las necesidades de apoyo y orientación que tiene el tesista son sólo de orden conceptual, por lo que se limitan a dar pautas sobre la composición escrita a partir de esquemas muy generales de tipo formal o estructural, lo cual se refleja en la Unidad del programa seminario de tesis denominada "aspectos ligados al género del escrito", específicamente en los puntos: "c) La estructura del escrito: portada, índice general, lista de tablas, introducción, cuerpo, conclusiones, apéndices, bibliografía. d) Características de las tesis y su 'traducción al libro' y en la Unidad 4 Aspectos lógicos, semánticos y éticos".

Por otra parte, en la metodología del seminario "conceptualización sobre investigación" de la MCE sigla con la que se nombra la maestría de Colombia, se plantea "evaluar un estado del arte de la idea de investigación y la argumentación de su elección sobre el tipo de investigación a emprender a la luz de los conceptos vistos", lo cual implica la 
puesta en marcha de habilidades avanzadas de escritura académica , sin embargo, no se explicita si el docente aparte de profundizar en las preguntas que realice el estudiante, también propicia espacios frecuentes de interacción entre él y los maestrandos y entre estos y sus pares para la revisión permanente de lo escrito, y soportar u andamiar así este proceso de escritura, por lo tanto, dicha práctica de escritura demandada al estudiante enfatiza en su función meramente evaluativa.

Otra variable a considerar en el análisis de los programas es su orientación metodológica, si esta obedece a una perspectiva amplia o estrecha de la ciencia, y para determinar estos valores, se tienen los indicadores concepción monista y concepción crítica, en el análisis del programa del seminario "concepciones sobre investigación" de la MCE, se evidencia el primer indicador, dado que este propone la "distinción entre investigación cualitativa y cuantitativa" promoviendo así la línea divisoria de la que habla Ynoub (2012), entre la orientación cualitativa y cuantitativa que las hace no sólo distintas en sus rasgos, sino antagónicas, lo cual es cuestionado desde una perspectiva crítica de la metodología científica, con base en la cual se busca comprender la lógica del proceso de investigación científica en general, trascendiendo las cuestiones meramente procedimentales del método científico. Desde dicha perspectiva crítica, la docente del módulo "metodología de la investigación" de la MIC estructura su programa, al considerar en este reflexiones en torno a las condicionantes históricos, sociales y culturales que posibilitan la ciencia y su método, lo cual faculta al estudiante para la toma de decisiones metodológicas conscientes y sustentadas en criterios epistemológicos claros y no sólo siguiendo los pasos que le indica un manual, sin embargo, el enfoque que orienta su práctica educativa es tradicional en la medida en que no hay solicitud explicita de articulación de este módulo con la tesis del maestrando.

\section{Análisis Nivel Subunitario Encuestas Estudiantes y Egresados}

Para el 57\%, de la MIC el plan de tesis sólo puede entregarse una vez aprobados y finalizados todos los modulos, el $4 \%$ de la MIC y $28 \%$ de la MCE consideran que debe entregarse al iniciar la maestría, para el 36\% de la MIC y el $32 \%$ de la MCE al cursar ciertas asignaturas.

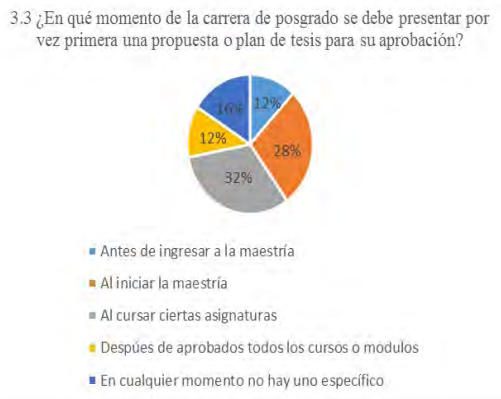

Figura 2. Pregunta 3.3 MCE

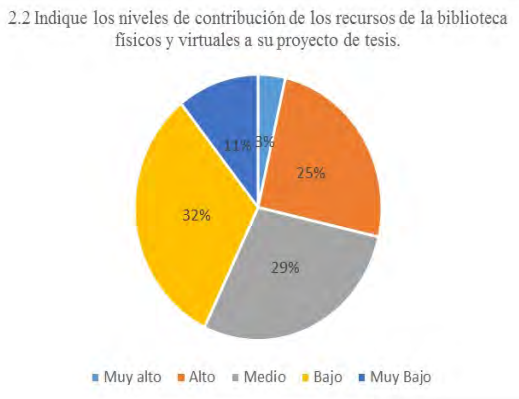

Figura 3. Pregunta 3.2 MIC 
El $33 \%$ de los encuestados de la MCE consideran que el anteproyecto o el plan de tesis no tiene una correspondencia con el documento que finalmente fue o será entregado para ser sustentado. Esto da cuenta que las asignaturas dirigidas a estructurar este, no constituyeron para todos escenarios posibilitadores para el avance significativo de sus tesis.

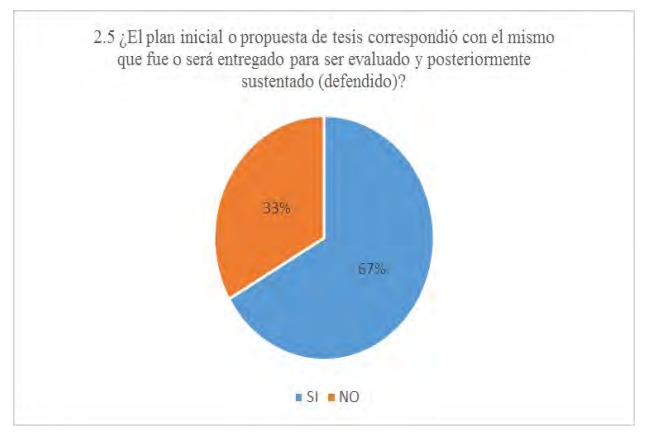

Figura 4. Pregunta 2.5 MCE

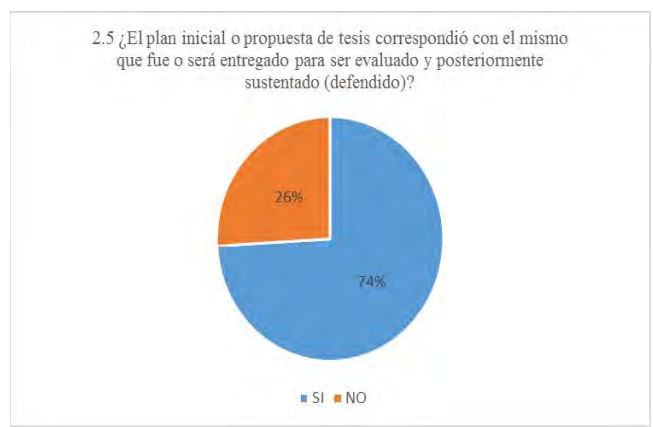

Figura 5. Pregunta $2.5 \mathrm{MIC}$

Para el 85\%, una mayoría de los encuestados de MIC, sus tesis no se adscriben a las líneas de investigación o proyectos del programa, contrario a la MCE donde el $83 \%$ si lo hacen.

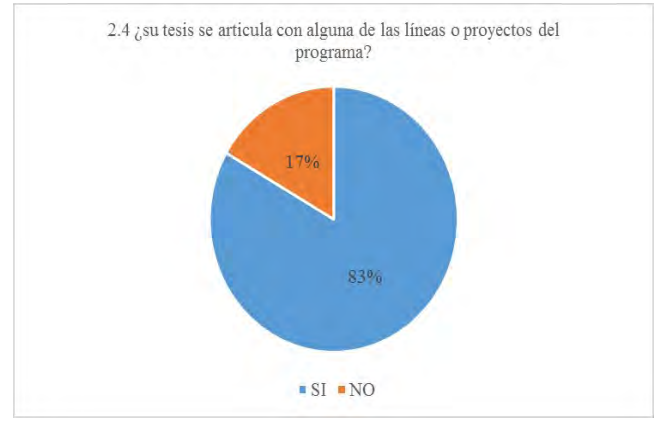

Figura 6. Pregunta 2.4 MCE

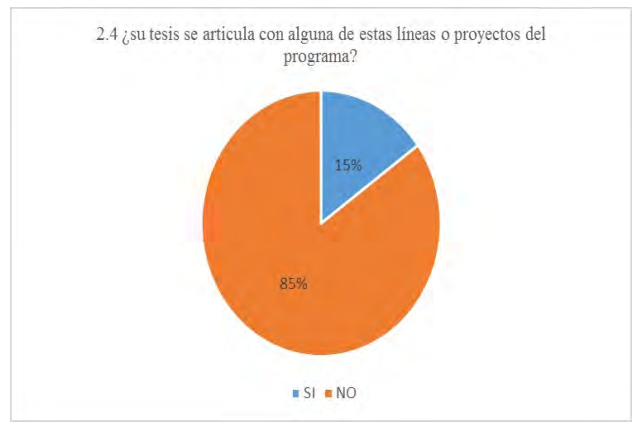

Figura 7. Pregunta 2.4 MIC

El $47 \%$ de los encuestados MIC consideran que el proceso de búsqueda y elección del director de tesis es dificil y el $14 \%$ que es regular, pese a que un $64 \%$ contaban con experiencia en grupos o proyectos de investigación científica antes de su ingreso a la maestría, y podrían elegir allí sus directores. 
5.1 ¿Cómo califica el proceso de búsqueda y elección de director de tesis?

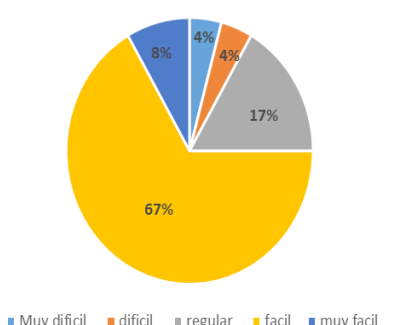

- Muy dificil dificil regular facil muy facil
5.1 ¿Cómo califíca el proceso de búsqueda y elección de director de tesis?

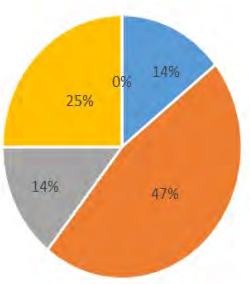

- Muy dificil a dificil " regular = facil = muy facil

Figura 8. Pregunta 5.1 MCE

Figura 9. Pregunta 2.5 MIC

En la MCE el 52\% más de la mitad no tenían la experiencia investigativa, sin embargo, el $67 \%$, señalan que el proceso de búsqueda de director es fácil.

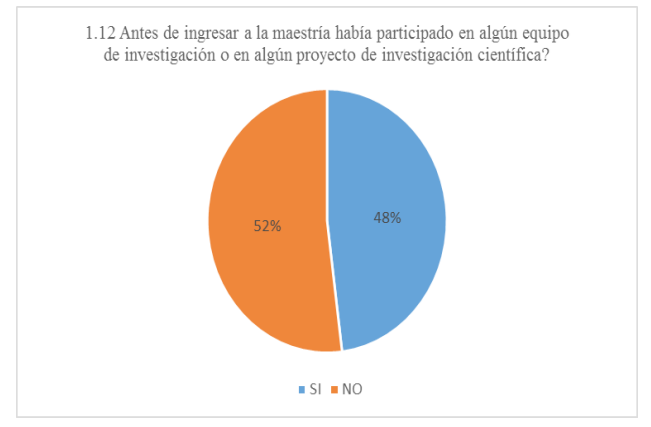

Figura 10. Resultado MCE

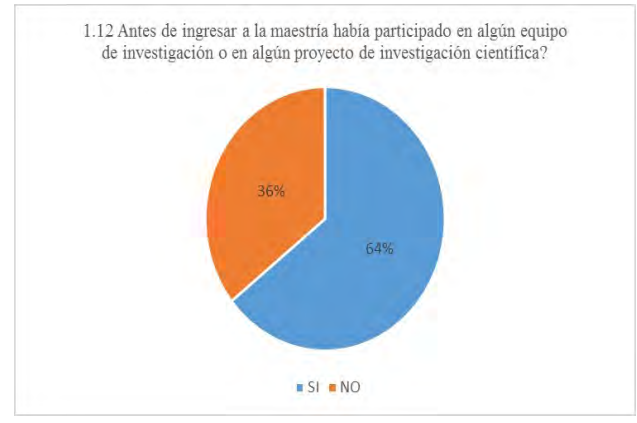

Figura 11. Resultado MIC

Para el 32\% de la MIC el nivel de contribución de los recursos bibliográficos dispuestos por la institución, a su proyecto de tesis, fue bajo y para el 48\% de la MCE es medio.

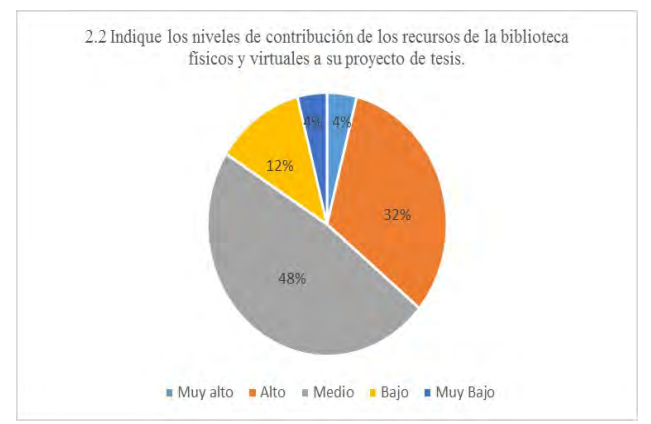

Figura 12. Pregunta 1.12 MCE

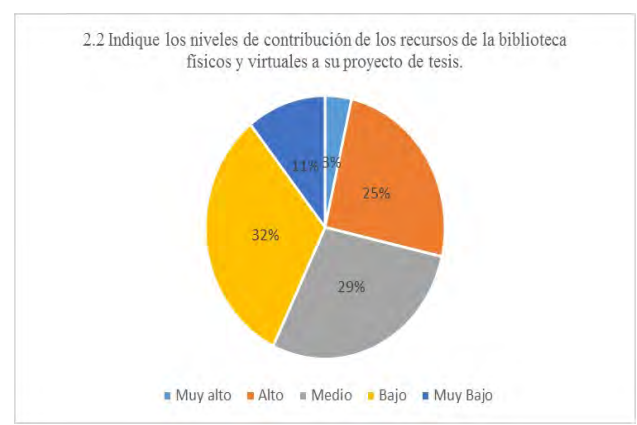

Figura 13. Pregunta 1.12 MIC

Para el 63\%, de la MIC, transcurrieron más de 2 años, desde el momento de la aprobación del plan de tesis hasta su defensa o sustentación y para los egresados de la MCE menos de 2 años. 


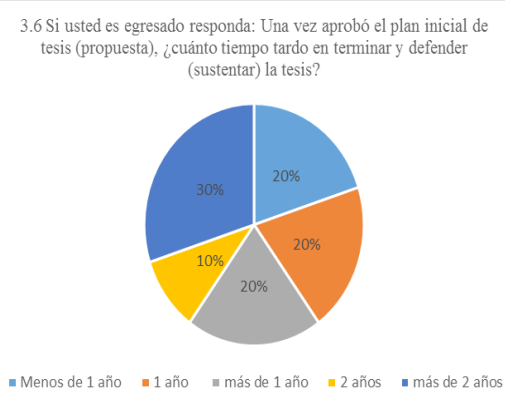

Figura 14. Pregunta 3.6 MCE

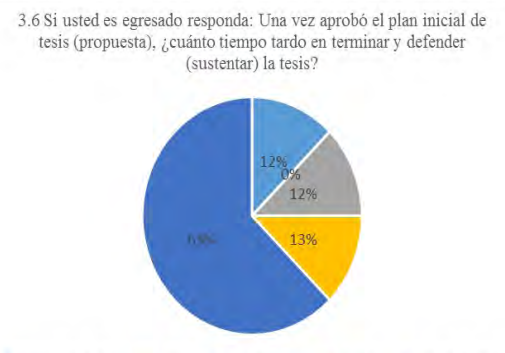

\Menos de 1 año = 1 año a más de 1 año = 2 años a más de 2 años

En la MIC el 39\% el nivel de aporte del seminario de tesis a la escritura del plan de tesis, fue medio, pero un $61 \%$ lo consideraron entre alto y muy alto, para el $48 \%$ de la MCE el nivel fue medio, es decir no suficiente para responder eficazmente al reto de escribir una tesis.

4.3 Indique el nivel de aporte de los seminarios o asignaturas de tesis, a la escritura de su propuesta inicial o plan de tesis

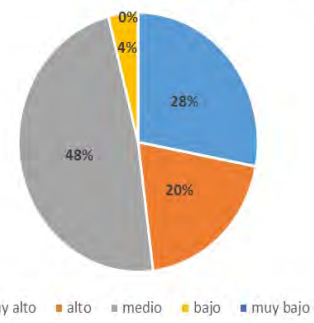

Figura 16. Pregunta 4.3 MCE
4.3 Indique el nivel de aporte de los seminarios o asignaturas de tesis, a la escritura de su propuesta inicial o plan de tesis

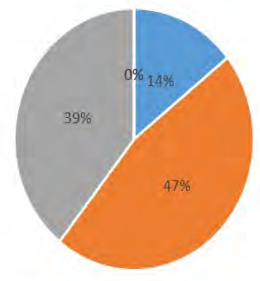

- muy alto alto medio = bajo muy bajo

El 48\%, de la MIC consideraron que durante la maestría leían y escribían principalmente, para dar cuenta de contenidos de la asignatura a través de una evaluación escrita, y en la MCE el 33\%,.

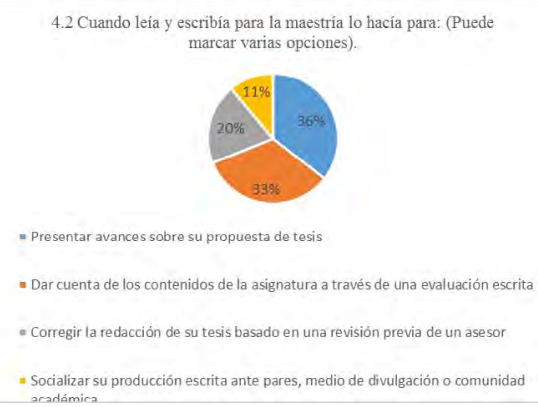

Figura 18. Pregunta 4.2MCE
4.2 Cuando leía y escribia para la maestría lo hacia para: (Puede marcar varias opciones).

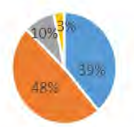

- Presentar avances sobre su propuesta de tesis

- Dar cuenta de los contenidos de la asignatura a través de una evaluación escrita

" Corregir la redacción de su tesis basado en una revisión previa de un asesor

- Socializar su producción escrita ante pares, medio de divulgación o comunidad

Figura 19. Pregunta 4.2 MIC 
Sólo un $10 \%$ consideraron que cuando leía y escribía para la maestría lo hacía para corregir la redacción de su tesis basado en una revisión previa, y un 3\% para socializar su producción escrita en algún medio de divulgación.

\section{Resultados Pruebas de Hipótesis}

A continuación, se presentan las pruebas cuyos resultados arrojaron que existe evidencia estadística suficiente para afirmar algunas de las hipótesis del estudio.

La siguiente prueba de hipótesis, contrastará la pregunta de la encuesta \#5.4: el Interés en el tema de tesis obedece a: (pueda marcar varias opciones)

\begin{tabular}{|c|c|}
\hline a) Motivación personal & 1 \\
\hline b) Motivación profesional & 2 \\
\hline c) Motivación social & 3 \\
\hline d) Sugerido por un docente o director de tesis & 4 \\
\hline $\begin{array}{l}\text { e) Articulado a líneas grupos o proyectos de in- } \\
\text { vestigación }\end{array}$ & 5 \\
\hline f) Otro ¿cuál? & 6 \\
\hline
\end{tabular}

En esta prueba se plantea contrastar el esperado de que la proporción de las o pciones a,b,c en la MIC sean mayor a un valor de proporción uniforme $\left(P_{o}=0, \sigma\right)$, es decir, estas opciones se presentarían con una proporción más significativa con respecto a las demás. La prueba de hipótesis se configura de la siguiente manera, utilizando un nivel de significancia $a=5 \%$, una distribución normal estándar $Z$ y utilizando el método del valor crítico para un tamaño de la muestra $n=54$ :

$$
\begin{aligned}
& H_{o}: P \leq 0.6 \\
& H_{a}: P \leq 0.6
\end{aligned}
$$

Para esta prueba Unilateral Derecha, el valor crítico $. z_{c}=1.64$. Luego de consolidar las encuestas, se calcularon los siguientes estadísticos:

$$
\begin{aligned}
& P=0.7407 \\
& z_{p}=\frac{\frac{P-P_{o}}{\sqrt{ } P_{o}\left(1-P_{o}\right)}}{n}=2.111
\end{aligned}
$$




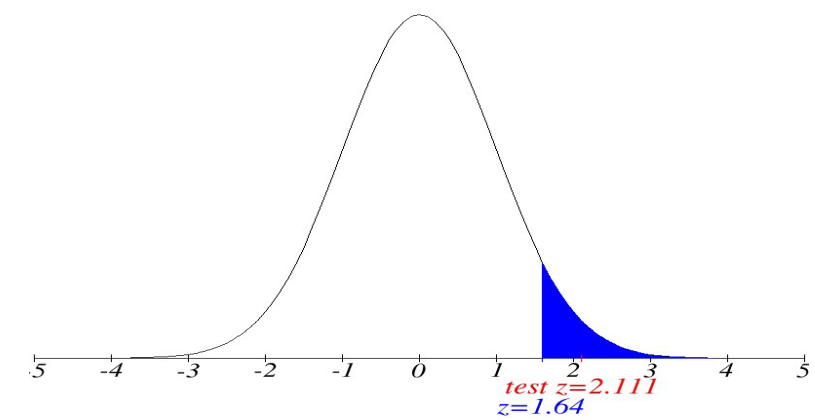

Figura 20. Prueba de Hipótesis Pregunta 5.4 MIC

Luego de calcular el valor de prueba $z_{p}$ y compararlo con $z_{c}$, se encuentra que: $z_{p}>z_{c^{\prime}}$ y cae en la región crítica, como se muestra en la Figura 27. De esta figura se concluye que existe evidencia estadística suficiente para afirmar que: el interés en el tema de tesis en su mayoría obedece a las opciones a, b y c en los estudiantes en la MIC, es decir, son mayoría significativa con respecto a las opciones sugerido por docente o articulado a líneas.

La siguiente prueba de hipótesis, contrastará la pregunta de la encuesta \# 4.2: Cuando leía y escribía para la maestría lo hacía para: (Puede marcar varias opciones).

La siguiente prueba de hipótesis, contrastará la pregunta de la encuesta \# 4.2: Cuando leía y escribía para la maestría lo hacía para: (Puede marcar varias opciones).

\begin{tabular}{|l|}
\hline a. Presentar avances sobre su propuesta de tesis \\
\hline $\begin{array}{l}\text { b. Dar cuenta de los contenidos de la asignatura a través de una } \\
\text { evaluación escrita }\end{array}$ \\
\hline $\begin{array}{l}\text { c. Corregir la redacción de su tesis basado en una revisión } \\
\text { previa de un asesor }\end{array}$ \\
\hline $\begin{array}{l}\text { d. Socializar su producción escrita ante pares, en un algún } \\
\text { medio de divulgación o ante una comunidad académica }\end{array}$ \\
\hline e. Otro ¿̇cuál? \\
\hline
\end{tabular}

En esta prueba se plantea contrastar el esperado de que la proporción de la opción b sea mayor a un valor de proporción uniforme $\left(P_{o}=0.2\right)$, es decir, la opción b se presentaría con una proporción significativa con respecto a las demás.

La prueba de hipótesis se configura de la siguiente manera, utilizando un nivel de significancia $a=5 \%$, una distribución normal estándar $Z$ y utilizando el método del valor crítico para un tamaño de la muestra $n=91$ :

$$
\begin{aligned}
& H_{0}: P \leq 0.2 \\
& H_{a}: P \leq 0.2
\end{aligned}
$$


Para esta prueba Unilateral Derecha, el valor crítico $z_{p}=1.675$. Luego de consolidar las encuestas, se calcularon los siguientes estadísticos: ${ }^{p} P=2.3018$

$$
z_{p}=\frac{\frac{P-P_{o}}{\sqrt{ } P_{o}\left(1-P_{o}\right)}}{n}=3.879
$$

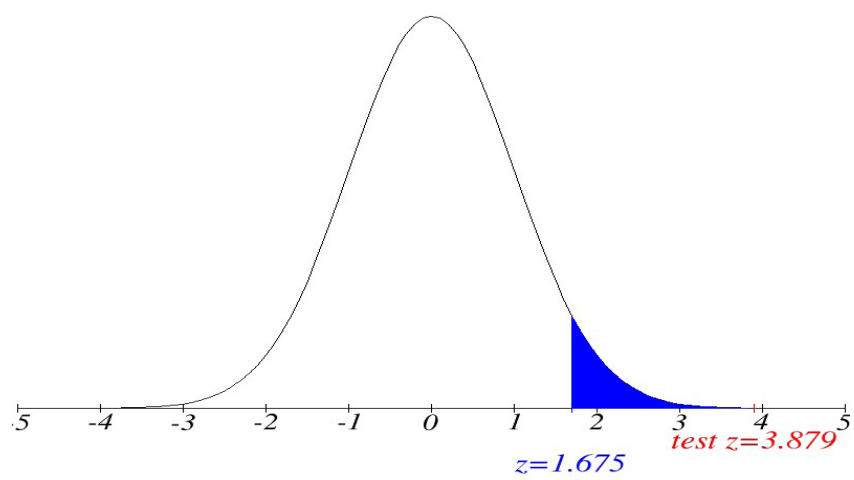

Figura 21. Prueba de Hipótesis Pregunta 4.2

Luego de calcular el valor de prueba $z_{p}$ y compararlo con $z_{c}$, se encuentra que $z_{p}>z_{c}$ y cae en la región crítica, como se muestra en la Figura 2. De esta figura se concluye que existe evidencia estadística suficiente para afirmar que ante la pregunta 4.2: Dar cuenta de los contenidos de la asignatura a través de una evaluación escrita de los estudiantes en la MIC y en la MCE es mayoría significativa con respecto a las demás opciones.

\section{Entrevistas Directores y Docentes}

El discurso de la directora de la MCE, da cuenta de una visión tradicional de universidad (ideal humboltiano), desde la cual se entiende la investigación como una actividad inherente a la formación universitaria especialmente a nivel de posgrado, por lo tanto, no está de acuerdo con la clasificación de las maestrías, en profesionales y de investigación "no existen maestrías profesionalizantes ni maestrías de investigación, una maestría es para que usted investigue" (Directora MCE, comunicación personal, 10 de febrero de 2017).

La directora MIC, asume una postura crítica frente a esta clasificación al reconocer los prejuicios alrededor de las tesis de maestrías profesionales. "Siempre esta ese prejuicio de que si es profesional no tiene que ser argumentativa puede no tener mucho aparato crítico, no tiene que tener muy en claro sus marcos teóricos, lo cual es falso para cualquier tesis" (Directora MIC, comunicación personal, 14 de febrero de 2017).

Si bien, la directora MIC se muestra de acuerdo con la clasificación de las maestrías establecida por la nueva normativa, es crítica de los estereotipos usados para distinguir entre la formación académica y la profesional, provenientes de un paradigma científico 
dominante que ha relegado a las disciplinas consideradas profesionales del campo de la investigación "[...] es necesario clasificar, pero también es bueno ver hasta donde esas clasificaciones no se transforman en un obstáculo, sobre todo si se arrastran ciertos prejuicios instalados por la tradición positivista" (Directora MIC, comunicación personal, 14 de febrero de 2017). El docente MIC ilustra una de las dificultades que trae para un tesista tales prejuicios, [...] estudiantes de la maestría que provienen de las ingenierías, que son ingenieros, una de las cosas que se advierte en ellos es la dificultad que se les plantean para acceder y para participar de ese mundo académico [...] (Docente MIC, comunicación personal, 19 de marzo de 2017).

Es mediante la tesis que el maestrando independiente del tipo de maestría o de su disciplina de proveniencia, logra acceder a este mundo académico, así lo plantea el docente MIC cuando señala que " [...] las tesis finalmente son tesis académicas, no son tesis profesionales porque lo que se requiere es una tesis académica y los son, aun hechas por ingenieros [...]". Arnoux \& Stefano (2003) mencionan que " $[. .$.$) los escritos de$ posgrado demandan una extensión, un nivel de conceptualización original, un grado superior de integración de conocimientos." (p.2)

La directora MIC señala las ventajas de la actual normativa en un momento de expansión masiva de maestrías, para la cual no estaban preparadas las universidades, debido a una oferta de posgrados concentrada en los doctorados, y a una normativa que no distinguía claramente entre las tesis de maestría y de doctorado "Antes parecía que todas las tesis tenían que ser como una tesis de doctorado, eso provoca una gran frustración, porque no todo el mundo está preparado para hacer un trabajo qué podría ser de 300 páginas", (Directora MIC, comunicación personal, 14 de febrero de 2017).

De este modo, una nueva norma que legitime tesis, que en palabras de la directora MIC sean "trabajos más cortos y más técnicos" tiene acogida en un sistema cuya tendencia ha sido academicista, a diferencia de los posgrados en Colombia que se han caracterizado por una tendencia profesionalista dado que su tradición ha sido en las especialidades, muchas de ellas, se convirtieron en maestrías precisamente como estrategia para suplir el déficit de investigadores en este país.

El discurso de la directora MIC sobre esta amplitud de posibilidades del tesista, se adentra en el terreno de lo metodológico, en la medida en que se plantean otros modos de construir conocimiento y por ende de hacer una tesis, que ponen en cuestionamiento la metodología como reducida a una receta a seguir por el investigador. "[...] tratamos de dar una concepción ampliada de la epistemología y de la metodología, para no caer en cuestiones de manual o cuestiones reduccionistas y que se termine haciendo una investigación estandarizada”. (Directora MIC, comunicación personal, 14 de febrero de 2017).

Este cuestionamiento al prescriptivismo en investigación, da cuenta del enfoque crítico que orienta la metodología de las tesis en este programa interdisciplinario, "[...] cuestiones de arte, cuestiones de atención a problemas de salud, a problemas sociales, de educación; ese tipo de tesis requieren una mirada interdisciplinaria, no podría resolverse con una metodología simplificada a una receta de pasos". (Directora MIC, comunicación personal, 14 de febrero de 2017). [...] cuando vos tenés, como tenemos nosotros, 
una maestría interdisciplinaria, entonces aquello del monismo metodológico, de que hay un solo método para todas las ciencias, ya no corre desde muchos lugares [...], (Docente MIC, comunicación personal, 19 de marzo de 2017).

La articulación de las tesis de los maestrandos a líneas o proyectos de investigación del programa, en la MCE se contempla desde el momento de la entrevista de admisión al programa. "[...] hay un proceso de selección con una entrevista donde se presentan los primeros intereses de investigación, se revisa si tiene que ver con las líneas que maneja la maestría en investigación" (Docente MCE, comunicación personal, 6 de marzo de 2017).

La docente MCE también habla de su rol en el proceso de acreditación de alta calidad de la maestría, consolidando mediante un seminario, la línea de investigación a la cual se vinculen las tesis de los estudiantes.

[...] darle continuidad a los seminarios de TIC y educación durante 3 semestres donde se vaya dando forma al proceso del documento de tesis de grado, eso es una oportunidad para ayudarles ya sea que se vinculen a la línea de investigación [...], (Docente MCE, comunicación personal,6 de marzo de 2017).

De este modo, la docente MCE pretende que las actividades de lectura y escritura propuestas en este seminario permitan a todos los estudiantes avanzar en su investigación, incluso a quienes no la vinculen a esta línea.

[...] todos los productos o los o las experiencias que aquí yo les propongo, las desarrollan encaminadas a su investigación, a sus intereses, porque de eso se trata, que avancen de alguna manera en el seminario, en sus líneas de investigación, sin importar si van a continuar con TIC o no [...]

Pero si los estudiantes no enganchan a esta línea sus tesis, tal pretensión de la docente se pone en duda desde un enfoque socio cultural, y como ella misma lo menciona terminarán haciendo la tarea para el seminario, debido a lo artificial que resulta esta práctica y al énfasis dado al producto textual más que al proceso intelectual implicado en la escritura, Carlino (2013).

[...] cuando el estudiante se queda en los seminarios haciendo las tareas, por cumplir la tarea del seminario, por eso la escritura se va a complicar un poco $[\ldots]$

[...] encontraremos los estudiantes que solamente hacen la tarea, tú sabes que en todos los contextos encontramos estudiantes de todo tipo, pero encontramos los estudiantes que en su mayoría tienen clarísimo que cada seminario es una oportunidad de avanzar en su interés [...], (Docente MCE, comunicación personal, 6 de marzo de 2017).

El discurso de la docente MCE, sobre los casos de éxito o fracaso en la escritura de las tesis, deja ver que la responsabilidad de aprovechar el potencial epistémico de las prác- 
ticas de lectura y escritura, recae directamente en el estudiante. Carlino (2008) afirma que es común en los profesores de las universidades, atribuir las dificultades de escritura a la responsabilidad individual del estudiante o a déficits en la enseñanza en niveles educativos previos, $[\ldots]$ yo creo que la lectoescritura va con los niveles de competencia intelectual usted no es capaz de escribir porque usted intelectualmente tiene muy bajos sus niveles de [...] habilidades superiores de pensamiento [...] (Directora MCE, comunicación personal, 10 de febrero de 2017).

[...] para la escritura de una tesis, un elemento fundamental que no tiene que ver con el ambiente de aprendizaje, sino ya más con la autonomía del estudiante. [...] un momento inicial sería autonomía, pero eso ya es más desde comportamientos ya personales como investigador.

Estos testimonios, contradicen los planteos de Arnoux (2006) de que el tesista irá avanzando en la autonomía de manera progresiva, es decir que no es una condición previa y "Las demandas cognitivas y discursivas que el proceso de escritura de tesis impone deben ser objeto de un tratamiento sistemático en espacios pedagógicos destinados a ello" (p.2).

Aunque el factor de tipo individual y psicológico tiene relevancia en el análisis de los procesos de desarrollo y aprendizaje, desde la perspectiva socio cultural, ambos son el resultado de un proceso de apropiación cultural, " [...] si bien es cierto que el desarrollo puede constatarse en el nivel del individuo, sería errado atribuirlo al resultado de un proceso individual." (Baquero, 2006, p.131). Para Reisin \& Carlino (2009) “ [...] la expectativa de autonomía que los directores depositan en los maestrandos" (p. 370) se liga con la idea de que el éxito o el fracaso es consecuencia de atributos individuales que portarían los estudiantes y no como " [...] resultado de la interacción entre los actores institucionales, en situaciones contextuales auténticas que los involucran”. (Lave, 2001 citado por Carlino 2009).

Entre las estrategias que han encontrado las instituciones para mejorar las estadísticas sobre la tasa de graduados en las maestrías, se encuentran los seminarios de tesis o de redacción.

[...] cambiar el plan de estudios y sacrificar un módulo para ampliar las horas del seminario de tesis y los seguimientos a la redacción de la tesis, es decir, a toda esa parte se le dio mayor peso dentro de las horas totales de la maestría, se transformó en un seminario de 5 meses, justamente para poder afianzar mejor la formación en la redacción de tesis, (Directora MIC, comunicación personal, 14 de febrero de 2017).

Sin embargo, Carlino (2013) plantea que la escritura de las tesis no debe ser sólo una preocupación de los docentes que orientan un módulo, ni enseñar la escritura como si se tratara de una habilidad básica generalizable a todas las disciplinas es decir "desligada del contenido de aquello sobre lo que se escribe" (p. 363), sino que cada curso debe convertirse en una oportunidad para acceder a la cultura escrita de su disciplina, y esto "implica una formación prolongada, no puede lograrse desde una única asignatura ni en un solo ciclo educativo" (p. 370), además la estrategia se vuelve contraproducente para las instituciones dado que " [...] la existencia de un espacio curricular específicamente dedicado a la 
lectura y/o escritura puede crear la ilusión de que está cubierta su necesidad de enseñanza, y entonces desresponsabilizar al resto de la institución y de docentes." (p. 263).

De este modo, la función que cumplen estos usos de la escritura, puede ser de tipo epistémico, es decir que posibilita la construcción de saberes en torno al tema de la tesis, o sólo evaluativa, escribir para responder a un examen. En la MIC se identifica una intencionalidad de promover usos epistémicos al invitar a la escritura con fines de publicación en las comunidades académicas.

[...] la cantidad de las cosas que publica Cuadernos de Trabajo y la revista Perspectivas Metodológicas son hechos por gente que está cursando la maestría o que ya tiene en claro su tema de tesis y que a veces cuando terminan de defender la tesis arman un artículo para poder publicarlo", (Directora MIC, comunicación personal, 14 de febrero de 2017).

El indicador articulación entre las tesis y los proyectos desarrollados al interior del programa se identifica en los denominados macroproyectos de investigación, los cuales operan muy semejante a una verdadera comunidad de práctica, debido a que los maestrandos mediante sus tesis aportan a una fase o parte de este megaproyecto, además, aquí el supuesto "déficit de autonomía" del alumno no sería obstáculo, dado la sistematicidad de los encuentros entre tesistas y líderes de los mega proyectos, pues como afirma Carlino, 2008. "La persistencia de los tesistas depende del sostén de las múltiples comunidades en las que participan” (p. 28)

[...] hemos hecho algunas estrategias con el fin de que la gente no se quede tanto tiempo en la maestría, o sea realmente lograr graduación .... yo he sido la autora de macroproyectos al lado de las líneas de investigación, (Directora MCE, comunicación personal, 10 de febrero de 2017).

[...] entre un grupo tienen un gran macroproyecto y dentro de ese gran macroproyecto se vinculan a hacer partes de la investigación.

[...] una forma de apoyar a los que tienen estas dificultades, vincularlos a macroproyectos obviamente tiene la misma rigurosidad y todo el acompañamiento, los momentos de encuentro son más, hay más, para los que no tienen tanta autonomía, (Docente MCE, comunicación personal, 6 de marzo de 2017).

En la MIC los maestrandos pueden vincularse a proyectos que adelanten los docentes del programa, y acreditar allí las horas de investigación exigidas a parte de las destinadas a la cursada de los módulos, no obstante, la dinámica aquí es distinta a la de los macroproyectos $\mathrm{MCE}$, pues si bien, la temática de las tesis de los maestrandos podría derivarse de estos proyectos, tanto su participación en estos, como la elaboración de su tesis ocurren en tiempos distintos.

[...] seguramente los que se sumaron a estas investigaciones y vayan a hacer tesis sobre las temáticas de estas investigaciones, las tesis van a aparecer 
dentro de 2 ańos o más". (Docente MIC, comunicación personal, 19 de marzo de 2017). [...] Son dos cosas distintas, una cosa es lo que vos haces, como investigación para la tesis, otra cosa es si vos participas dentro de un grupo de investigación que pueda hacer investigación en ese tema o en cualquier otro, (Directora MIC, comunicación personal, 14 de febrero de 2017).

\section{Discusión}

La no problematización del concepto de investigación como resultado de la reproducción de enfoques hegemónicos Van dijk (1999), se refleja en las definiciones que otorga el decreto a cada tipo de maestría, puesto que una de las dos es catalogada como "maestría de investigación", pese a que en la maestría de profundización, se apropian metodologías científicas como medio para lograr dar solución a problemas concretos, y además los trabajos de grado pueden dirigirse a investigación aplicada, para Diaz, E. (2000) "[...] la investigación aplicada también es búsqueda original, en el sentido de que se elaboran conocimientos nuevos, pero dirigidos ahora hacia algún objetivo práctico. Se trata de una transición hacia el uso de las teorías cient íficas." (p. 64).

Por otra parte, el concepto de tesis no es empleado en la normativa de Colombia, pese a decretar que los trabajos de grado en las maestrías de investigación deben [...] reflejar la adquisición de las competencias propias de un investigador académico", las cuales sólo se pondrían en marcha con la elaboración de una tesis, pues esta implica que haya "[...]cierto grado de originalidad en el tratamiento del tema" (Mombrú \& Margetic, 2013, p. 22).

La normativa argentina es más precisa en el lenguaje que utiliza, puesto que la tesis según la resolución, es el única opción válida como trabajo final para las maestrías académicas, pero también puede ser presentada como trabajo final en una maestría profesional junto con otras opciones, es decir, a través de las tesis se le da cabida a lo académico en estos posgrados.

Para el docente de la MIC los maestrandos de áreas como ingeniería y matemáticas presentan mayores dificultades para la escritura, sin embargo, desde una teoría de la alfabetización académica, tal dificultad no proviene del área, sino que tienen que ver con las pocas posibilidades de inserción del estudiante en la comunidad discursiva científica propia de su disciplina, en un programa interdisciplinario como lo es este.

La articulación de las líneas con los seminarios en la MCE, no garantiza el ingreso exitoso del tesista a su "comunidad discursiva científica", ya que los seminarios como lo muestran las estadísticas se caracterizan por la tradicional estructura monológica, que no promueve la participación de los tesistas en discusiones sobre lo escrito y lo leído (enseñanza dialógica) dado que se valora más el "producto textual" que el "proceso intelectual" de la escritura (Carlino, 2013), llevando al estudiante a adoptar un rol receptivo - pasivo, es decir que, como menciona la docente MCE, termina "haciendo la tarea para el seminario" en términos de Carlino (2013) "leer sin un genuino propósito", relegándose así el uso epistémico de la escritura. 
De este modo, actividades de escritura académica como socializar su producción escrita ante medios de divulgación o escribir para la tesis basado en revisiones previas de un asesor, en ambas universidades, no fueron tan representativas como leer y escribir para dar cuenta de los contenidos de la asignatura a través de una evaluación escrita.

Aunque en algunos seminarios se les convoque a emprender tesis relacionadas con una determinada línea de investigación del programa, para la docente MCE la responsabilidad de avanzar en la escritura de la tesis mediante las actividades de lectura y escritura que se proponen en los seminarios, recae especialmente en el estudiante, lo que va en contravía del planteo de Arnoux (2006), "Las demandas cognitivas y discursivas que el proceso de escritura de tesis impone deben ser objeto de un tratamiento sistemático en espacios pedagógicos destinados a ello". (p. 2)

Un elemento obstaculizador o favorecedor para la escritura de las tesis dentro de tiempos razonables, son los "potenciales directores de tesis" Carlino (2005), en la MCE el $67 \%$ de los encuestados, consideraron como fácil la búsqueda y elección de su director de tesis, a diferencia de la MIC donde según la prueba de hipótesis realizada existe evidencia estadística suficiente para afirmar que: el proceso de búsqueda y elección de director de los estudiantes en la universidad de Lanús está desde Regular a muy difícil.

Los esfuerzos por prevenir tal fracaso con las tesis, en la MIC, según testimonios de los directivos entrevistados, se han concentrado en el seminario de tesis, de este modo, es alto porcentaje de encuestados que consideraron que los seminarios de tesis contribuyeron en gran medida a la elaboración de su plan de tesis.

Los resultados de las encuestas de la MIC muestran que la experiencia investigativa no tiene relación con el tiempo que toma culminar una tesis, pues pese a que la mayoría habían participado previamente en un grupo de investigación, más del $60 \%$ tardaron más de 2 años, en la MCE un poco más de la mitad, el 52\%, no habían participado en grupos de investigación y aun así sólo el 30\% tardaron más de 2 años en terminar y defender su tesis una vez aprobado el plan o propuesta, el $50 \%$ tardaron entre 1 año y 2 años y el $20 \%$ restante menos de 1 año.

En la MIC un $85 \%$ de los encuestados consideran que sus tesis no se adhieren a las líneas de investigación trabajadas por docentes al interior de los programas, en la MCE el $83 \%$ consideraron que si se adhieren, dato que se analiza en relación con la edad promedio de los estudiantes de ambos programas, ya que en la MIC la edad oscila entre los 50 y 60 ańos y en la MCE entre los 30 y 40 años, en este último rango se ubican adultos más jóvenes que apenas se insertan a estas comunidades académicas, pues más del 50\% de los encuestados de la MCE no contaba con experiencia en grupos o líneas de investigación antes de su ingreso a la maestría, a diferencia de la MIC donde más del 60\% de encuestados debido a su trayectoria ya se encontraban adheridos a líneas y proyectos de investigación antes de su ingreso.

La vinculación a proyectos o líneas resulta facilitador para aquellos novatos que no cuentan con carrera investigativa previa, como la población de la MCE, ya que como afirma Lave (1991) van ganando "centralidad" en sus "comunidades de práctica" partici- 
pando en actividades científicas genuinas con miembros de la comunidad más experimentados, sin embargo, en estos países donde hay gran expansión de la oferta y demanda de maestrías especialmente en las ciencias sociales, las capacidades institucionales son limitadas y no alcanzan a suplir las necesidades de asesoría y dirección de tesis de este crecie nte número de jóvenes maestrandos.

A modo de conclusión y como solución a la "ausencia de un ámbito institucional organizado por la maestría para el seguimiento de las tesis" (Carlino y Reisin, 2009, p. 369), se recomienda que desde los programas se dispongan acciones que acompañen la labor del tesista durante todo el periodo de cursada.

\section{Bibliografía}

- Arnoux, E., Carlino, P., Di Stefano, M., Nogueira, S., Vitale, S., Martínez, A., Hidalgo, C. y Pereira, C. (2003). "Escritura y producción de conocimiento en las carreras de posgrado". Ponencia presentada en el $I I^{\circ}$ Congreso Internacional Cátedra UNESCO Lectura y Escritura Comprensión y producción de textos escritos: de la reflexión a la práctica en el aula. Pontificia Universidad Católica de Valparaíso, Chile, 5 al 9 de mayo de 2003.

- Arnoux, E. (2006). "Incidencia de la lectura de pares y expertos en la reescritura del trabajo de tesis". RLA, Concepción, Chile, 44(1), 95-118.

- Baquero, R. (2006). Sujetos y aprendizaje. Buenos Aires: Ministerio de Educación, Ciencia y Tecnología de la Nación.

— Carlino, P. (2013). "Alfabetización Académica diez años después”. Revista mexicana de investigación educativa, 18(57), pp. 355-381.

- Carlino, P. (2008). "Revisión entre pares en la formación de posgrado". Lectura y Vida, 29(2), pp. 20-31.

- Carlino, P. (2005). “¿Por qué no se completan las tesis en los postgrados?:Obstáculos percibidos por maestrandos en curso y magistri exitosos". Educere, Revista venezolana de educación superior, 9(30), pp. 415-420.

- Carlino, P. (2004). "El proceso de escritura académica: cuatro dificultades de la enseñanza universitaria”. Educere. Revista venezolana de educación superior, 8(26), pp. 321-327.

- Carlino, P. (2003). "La experiencia de escribir una tesis: contextos que la vuelven más difícil”. Anales del Instituto de Lingüistica, xxiv-xxv-xxvi, pp. 41-62.

- Diaz, E. (2000). "Investigación básica, tecnología y sociedad. Khun y Foucault". En E. Díaz, (Ed.). La posciencia. El conocimiento científico en las postrimerías de la modernidad. Buenos Aires: Biblos.

— Hernández, G. (2009). "Escritura Académica y Formación de maestros ¿por qué no acaban las tesis?”. Revista Tiempo de Educar, 10(19), pp. 11-40.

- Jaramillo. H. (2009). "La formación de posgrado en Colombia: maestrías y doctorados". Revista CTS, Vol. 5, No. 13, pp. 131-155. 
— Larreamendy. J. (2011). “Aprendizaje como reconfiguración de agencia”. Revista de estudios sociales, (40), pp. 33-43.

- Larreamendy. J. (2007). Práctica conjunta e identidad en la actividad científica: El trabajo de campo en biología como escenario de aprendizaje. Bogotá: Universidad de los Andes, CESO, Facultad de Ciencias Sociales.

- Ochoa, L. \& Cueva, A. (2012). Tesis y deserción: entre el compromiso y el obstáculo. Bogotá: Editorial UN.

— Lave, J. \& Wenger,E.(1991). Situated Learning: Legitimate peripheral participation. New York: Cambridge University Press.

- Mombrú, A. \& Margetic, A. (2013). El Hacedor de Tesis. Avellaneda: LJC Ediciones.

- Recalde, A. (2015). Dirección de posgrado Universidad Nacional de Lanús: Ingreso y egreso de alumnos de Posgrado en Universidades Estatales. Recuperado de: http://www.UNLa.edu.ar/documentos/posgrado/CausasdenoculminarTesis-TFI-1.pdf.

— Reisin, S., \& Carlino, P. (2009). "Factores que favorecen u obstaculizan la finalización de una maestría en ciencias sociales. El punto de vista de los involucrados". En I Congreso Internacional de Investigación y Práctica profesional en Psicologia XVI Jornadas de Investigación Quinto Encuentro de Investigadores en Psicología del MERCOSUR. Facultad de Psicología - Universidad de Buenos Aires.

- Samaja, J. (2010). Epistemología y Metodología. Elementos para una teoría de la investigación cientifica. Buenos Aires: Eudeba.

- Ynoub, R. (2015). Cuestión de método. Aportes para una metodología crítica. México: Cengage Learning editores.

- Van Dijk, T. A. (1999) "El análisis crítico del discurso". Anthropos, (186), pp. 23-36 